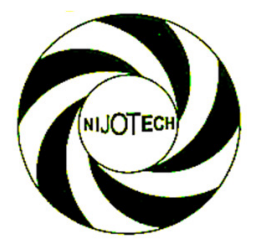

Nigerian Journal of Technology (NIJOTECH)

Vol. 34 No. 2, April 2015, pp. 272 - 279

Copyright(C) Faculty of Engineering,

University of Nigeria, Nsukka, ISSN: 111 15-8443

www.nijotech.com

http://dx.doi.org/10.4314/njt.v34i2.9

\title{
STOCHASTIC ASSESSMENT OF NIGERIAN WOOD FOR BRIDGE DECKS
}

\author{
P. A. Owoeye ${ }^{1}$ and O. S. Abejide ${ }^{2}$, . \\ 1,2 DePARTMENT OF Civil ENGINEERING, AHMAdU Bello UNIVERSITY, ZARIA. NIGERIA.

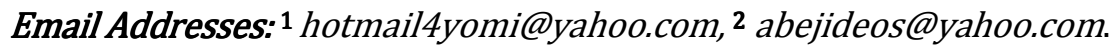

\begin{abstract}
This presentation assures the suitability of Nigerian wood using a stochastic safety evaluation method for bridge decks. A timber bridge deck is modeled in accordance to current specifications, to represent real life experiment in order to depict the structural behavior of planks when used as bridge decks. This model is then subjected to some degree of entropy using Advance Second Moment Reliability Assessment (ASMRA) method, which is then subsequently analyzed using JAVA library with the help of Flanagan polynomial. It is observed that, strength classes, timber thicknesses and stringer spacings are the major factors among others influencing the structural behavior of Nigerian timber species proposed as bridge decks material. Therefore, the major classes of the timber recommended for bridge decks are those within the strength classes $N_{1}$ to $N_{4}$ and with dimensions ranging from 100 $x 250 \mathrm{~mm}$ to $150 \times 300 \mathrm{~mm}$ on stringers spaced not greater than $300 \mathrm{~mm}$. These strength classes with their corresponding material properties can be a source of sustainable bridge decks material over a reasonable period of time as indicated by the probability of failure as a result of damage due to load accumulation. In view of this, timber which is a locally available material can be used as supplement for bridge decks to substitute for the expensive concrete and steel which are the most commonly used materials and substantially reduce the cost of decks. Also, abandoned bridges with defects only in their decks in both rural and urban locations can be effectively rehabilitated in order to improve traffic flow, economic activities and the quality of life of the people.
\end{abstract}

Keywords: Nigerian timber classifications, sizes and spacing, bridge decks, safety and Flanagan polynomial.

\section{INTRODUCTION}

The need for local content in the construction of engineering infrastructure is now a serious engineering challenge in Nigeria. This is because vast quantities of local raw materials, which must be processed and used for cost effective construction abound. Construction activities based on these locally available raw materials are major steps towards industrialization and economic independence for developing countries [1]. Wood is one of the naturally occurring raw materials which abound in Nigeria and it had been put to use as a building material for construction since prehistoric times. It is available in large quantities in the forested parts of the country [2].

It has been described [3] that timber is a low density, cellular, polymeric composite which does not fall into any one class of materials; rather it tends to overlap a number of classes and as a result of its high strength performance and low cost, timber was found to be the world most successful fiber composite. Thus with critical analysis of our environment and careful exploration of the structural properties of timber, one can adequately establish and design an environmentally friendly structure which is cost effective.

Reinforced concrete and steel which has edged out timber as a construction component for bridges was reported [4] as not been an everlasting material they were assumed to be. This according to him is because many countries have experienced serious problems with concrete bridges built that are between forty and fifty years old. This was backed with the assertions stated in VERMONT[5] local road fact sheet. It was clearly stated in this local fact sheet that, properly treated, timber is stable and durable under the most severe weather and site conditions, which is one of its attractive performance features for bridges as it is completely resistant to the deicing salts, decay and insect attacks. It had also been noticed[4], that deicing salts have caused significant and surprisingly rapid deterioration of both steel and concrete bridges and

\footnotetext{
* Corresponding Author, Tel: +234-803-590-8260
} 
components. Also when a larger structural timber is exposed to fire, there is some delay as it chars and eventually flames.

Treated timber bridge decks are built in days not weeks, because materials are low energy, certified, reusable and renewable, where components are shop manufactured under controlled conditions to maintain quality [6]. Due to the current dispensation and increased challenges in global development in all sectors of the economy, there exist these motives to build bridges faster that will last longer, for less money and with aesthetics appeal which has led to the quest for the perfect bridge material.

Currently, the use of timber as a bridge deck or bridge component has not been a common practice in Africa, although there are a few physical examples associated with scarce historical documentation in the forested areas of the country and Africa. This study of using timber for bridges brings to focus current reasoning and the integration of advanced technologies to suit the available climatic, natural and human resources to solve the problem of transportation, by making cheaper, better and more reliable structural systems in highways [7].

The use of this renewable composite and lightweight natural resource as a bridge deck, will not only be a new strategy for development in the third world and tropics but also as a sustainable development which will help to overcome the exclusion of timber technology in modern time, thereby strengthening its inclusion through research and practical applications. It is in this regard that this study assesses the possibility of employing various Nigerian timber species as innovative, sustainable and cost-effective materials for bridge decks and also evaluate the longterm performance and economic viability of Nigerian timber for rehabilitating abandoned bridges in order to open up old roads in urban and rural areasso as to promote interest in the use of wood as a competitive bridge construction material by adding value to the use of local resources forthe bridge construction industries.

\section{STUDY METHODOLOGY}

The concept of Advance Second Moment Reliability Assessment (ASMRA) method is used herein to evaluate the structural safety of various Nigerian timber species for bridge decks. This is because, there is need for a fully probabilistic approach to the safety assessment of structural timber decks, due tomany factors, such as climate, material composition and degradation of structural timber, occurrence of natural disasters and impacts of man-made technology control the existence of human beings and the quality of the surrounding environment of bridge decks[8]. Many of these quantities cannot be represented adequately by deterministic values or relationships, thus, the variability in these quantities need be included in models of both nature and the built environment $[8,9]$.

With adequate Probability Density Functions (PDF) to represent the possible variability of each individual random variable, the combined effect of these variables on the performance function of a bridge can be used to study the safety or possibility of using Nigerian timbers for bridge decks. The reliability which can be seen as the detection of rare physical events such as failures, which usually occur with low probability, play key roles in the probabilistic safety assessment of engineering structures [10].

\subsection{Plank Deck Structural Design Model}

A typical plank or timber deck consists of planks placed on stringers as shown in Figures 1 and 2, according to Nowak and Saraf [11]. There are two categories of plank decks depending on the direction of planks versus the direction of traffic: transverse deck and longitudinal decks. For a typical transverse plank deck the span of the deck is perpendicular to the direction of traffic.

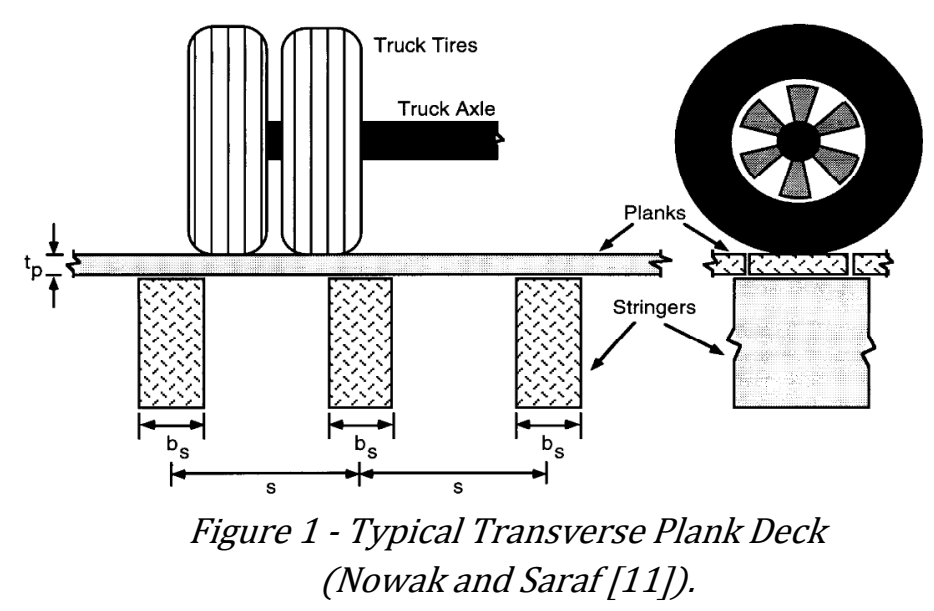

A longitudinal plank deck, as shown in Figure 2, is placed parallel to the direction of traffic. It is assumed that stringers have an adequate load carrying capacity and that they provide a sufficient support for planks. With reference to the American code [12], performance function for safety evaluationis developed as: 


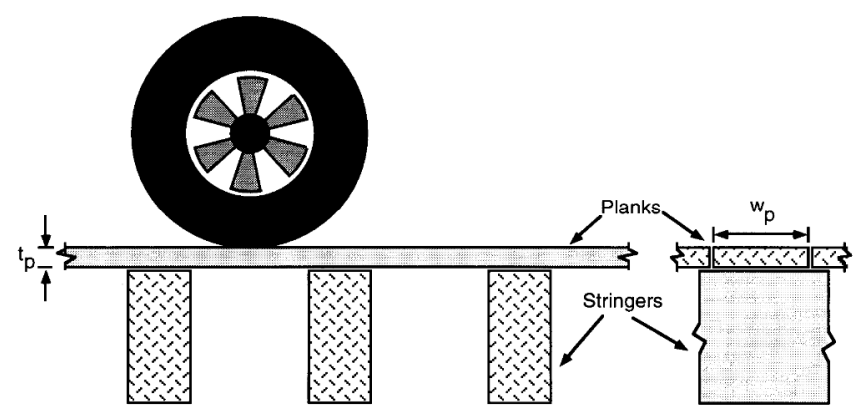

Figure 2 - Typical Longitudinal Plank Deck (Nowak and Saraf [11]).

$$
\begin{aligned}
f\left(x_{1}, x_{2},, x_{n}\right)= & 0.2667 f_{b o} w_{p} t_{p}^{2} C_{d} \\
& -0.15625 \rho_{p} w_{p} t_{p} s^{2} \\
& -0.1875 \rho_{s} w_{p} t_{s} s^{2} \\
& -0.21875\left\{P\left(2 s-b_{t}\right)\right. \\
& \left.+w_{l} s^{2}\right\}
\end{aligned}
$$

Equation (1) is for plank decks under flexure, where the depth of the flexural component does not exceed its width, or where lateral movement of the compression zone is prevented and where points of bearing have lateral support to prevent rotation. As a result of this, the structural performance of the plank deck is determined by loads and resistances.

\section{DAMAGE ACCUMULATION MODEL}

The damage accumulation model is used to mathematically describe the long term strength reduction as a function of stress level and duration of loading. Thus, the concept of Gerhards[13] model is adopted. Gerhards[13]opined that the rate of damage accumulation is exponentially dependent on stress level. A simple arithmetic solution to Gerhards[13] model has been given by Hoffmeyer[14], after testing hundreds of timber species with different construction sizes and various moisture contents. For timber decks, the working condition was assumed to be within the range of $11-20 \%$ moisture content. Therefore, the damage accumulation model was developed to be;

$$
\begin{aligned}
f\left(x_{1}, x_{2},, x_{n}\right)= & 88.5-7.85 \log _{10} t_{f} \\
& -4901.960784 \frac{p(t)}{f_{b}}
\end{aligned}
$$

This defines the possible time to failure for timber under the influence of load accumulation effect over time. Equation (2) will be used to assess the structural safety of the system under bridge load decks and stress level at a predictable time to failure (for instance, 50 years) in order to check the long term viability and economic performance of employing Nigerian timber for bridge decks. According to Melchers [15] the target reliability ( $\beta$ ) for timber members ranges from 2.0 to 3.0 with strong mean of 2.5. A target structural safety or reliability index of 2.5 was set to assess and predict the behavior of Nigerian timber when used as bridge deck under specific design conditions of loading and geometrical properties in accordance to the American code [12] specifications.

\subsection{Data Source}

Table 1 gives the detail of material quality for the timber species proposed for bridge decks. Note that $\mu$ is the mean of the variable data and $\sigma$ the standard deviation of the variables. Table 2 shows the stochastic and other suggested parameters for the timber materials evaluation.

\section{ANALYSIS AND RESULTS}

\subsection{General structural reliability assessment}

The general structural reliability assessment of using four Nigerian timbers (namely EKKI, APA, IROKO and ABURA) for bridge decks was executed in relation to

\begin{tabular}{|c|c|c|c|c|c|c|c|c|}
\hline \multicolumn{3}{|c|}{ Source and Names of Wood } & \multicolumn{2}{|c|}{$\begin{array}{l}\text { Flexural } \\
\text { Strength, } f_{b o} \\
\quad \text { Grade } \\
80) \mathrm{kN} / \mathrm{m}^{2} \\
\text { Lognormal }\end{array}$} & \multicolumn{2}{|c|}{$\begin{array}{l}\text { Unit Weight, } \rho_{t} \\
\quad\left(k N / m^{3}\right)\end{array}$} & \multirow[t]{2}{*}{$\begin{array}{l}\text { Strength } \\
\text { Group }\end{array}$} & \multirow[t]{2}{*}{ Durability } \\
\hline Data Source & Botanical Name & $\begin{array}{l}\text { Standard } \\
\text { Name }\end{array}$ & $\mu$ & $\sigma$ & $\mu$ & $\sigma$ & & \\
\hline $\begin{array}{c}\text { Aguwa\&Sadiku } \\
{[1]}\end{array}$ & Lophiraalata & Ekki & 29960 & 3295.6 & 11.33 & 0.6798 & $N_{1}$ & Very Durable \\
\hline Aguwa [7] & Afzeliabipindensis & Apa & 23940 & 3112.2 & 7.98 & 0.8778 & $N_{2}$ & Very Durable \\
\hline CIRAD [16] & Chlorophoraexceisa & Iroko & 18507 & 2525.5 & 6.40 & 0.6000 & $N_{3}$ & Very Durable \\
\hline CIRAD [17] & Mitragynaciliata & Abura & 14478 & 2375.9 & 6.00 & 0.500 & $N_{4}$ & Non-Durable \\
\hline
\end{tabular}
Equation (1) by ASMRA method using JAVA library with the help of Flanagan polynomial. The results obtained are displayed in Table 3.The safety index, $\beta$, is as obtained from the execution of ASMRA while employing Equation (1).

Table 1 -Dry Grade (80\%) Stress 
Table 2 - Other Design Data

\begin{tabular}{cccccc}
\hline \multirow{2}{*}{ Source } & \multirow{2}{*}{ Data } & \multicolumn{3}{c}{ Value } & \multirow{2}{*}{ Distribution Type } \\
\cline { 2 - 5 } & & $\mu$ & COV (\%) & $\sigma$ & Lognormal \\
\hline Nowak and Saraf[10] & Width of timber & $250-300 \mathrm{~mm}$ & 12 & 30.00 & Lognormal \\
Nowak and Saraf[10] & Timber thickness & $100 \mathrm{~mm}$ & 7 & 7.00 & Lognormal \\
Nowak and Saraf [11] & Stringer spacing & $300-600 \mathrm{~mm}$ & 23.33 & 70.00 & Lognormal \\
AAHSTO LRFD [12] & Unit weight of surfacing material & $22.426 \mathrm{kN} / \mathrm{m}^{3}$ & 24.53 & 5.5 & Normal \\
AAHSTO LRFD [12] & Surfacing thickness & $70 \mathrm{~mm}$ & 14.98 & 10.00 & Normal \\
AAHSTO LRFD [12] & Wheel load & $70 \mathrm{kN}$ & 14 & 9.8 & Lognormal \\
\hline
\end{tabular}

Table 3-Reliability of Nigeria timber (Ekki, Apa, Iroko And Abura).

\begin{tabular}{ccccccccc}
\hline$\beta$ & $f_{b o}$ & $w_{t}$ & $t_{t}$ & $\rho_{t}$ & $S$ & $\rho_{s}$ & $t_{s}$ & $P$ \\
\hline 4.51619 & 29960 & 0.25 & 0.1 & 11.33 & 0.3 & 22.426 & 0.07 & 70 \\
3.97876 & 22759.1651 & 0.17860 & 0.08070998 & 11.3301 & 0.41087 & 22.4329 & 0.07000 & 70.9440 \\
3.86841 & 24825.3080 & 0.20184 & 0.08539701 & 11.3302 & 0.49374 & 22.4399 & 0.07001 & 70.9734 \\
3.85186 & 25186.4961 & 0.20446 & 0.08669217 & 11.3303 & 0.51219 & 22.4459 & 0.07002 & 70.7435 \\
3.84950 & 25244.1376 & 0.20505 & 0.08685331 & 11.3304 & 0.51517 & 22.4518 & 0.07002 & 70.7003 \\
3.84916 & 25252.7246 & 0.20511 & 0.08688318 & 11.3305 & 0.51561 & 22.4576 & 0.07003 & 70.6935 \\
3.84911 & 25253.9364 & 0.20512 & 0.08688663 & 11.3306 & 0.51568 & 22.4634 & 0.07004 & 70.6925 \\
3.84910 & 25254.1332 & 0.20512 & 0.08688730 & 11.3307 & 0.51569 & 22.4692 & 0.07004 & 70.6923 \\
3.84910 & 25254.1584 & 0.20512 & 0.08688737 & 11.3308 & 0.51569 & 22.4750 & 0.07005 & 70.6923 \\
3.8491 & 25254.1636 & 0.20512 & 0.08688739 & 11.331 & 0.51569 & 22.4808 & 0.07005 & 70.6923 \\
& & & & & & & & \\
\hline & & & & APA & & & & \\
\hline 3.66764 & 23940 & 0.25 & 0.1 & 7.98 & 0.3 & 22.426 & 0.07 & 70 \\
3.25391 & 17872.6451 & 0.19597 & 0.08546123 & 7.98019 & 0.40362 & 22.4325 & 0.07000 & 70.8454 \\
3.19515 & 19832.8101 & 0.21171 & 0.08873686 & 7.98038 & 0.46550 & 22.4387 & 0.07001 & 70.7947 \\
3.18812 & 19991.2493 & 0.21367 & 0.08959614 & 7.98055 & 0.47604 & 22.4443 & 0.07001 & 70.6285 \\
3.18732 & 20023.2617 & 0.21394 & 0.08967215 & 7.98072 & 0.47739 & 22.4497 & 0.07002 & 70.6033 \\
3.18723 & 20025.2190 & 0.21397 & 0.08968478 & 7.98088 & 0.47755 & 22.4552 & 0.07003 & 70.6001 \\
3.18721 & 20025.7264 & 0.21397 & 0.08968579 & 7.98104 & 0.47756 & 22.4606 & 0.07003 & 70.5997 \\
3.18721 & 20025.7450 & 0.21397 & 0.08968598 & 7.98121 & 0.47757 & 22.4660 & 0.07004 & 70.5996 \\
3.18721 & 20025.7541 & 0.21397 & 0.08968599 & 7.98137 & 0.47757 & 22.4715 & 0.07004 & 70.5996 \\
3.18721 & 20025.7547 & 0.21397 & 0.08968600 & 7.98154 & 0.47757 & 22.4769 & 0.07005 & 70.5996
\end{tabular}

\begin{tabular}{ccccccccc}
\hline \multicolumn{7}{c}{ IROKO } \\
\hline 2.86339 & 18507 & 0.25 & 0.1 & 6.4 & 0.3 & 22.426 & 0.07 & 70 \\
2.55362 & 14714.6272 & 0.21032 & 0.08938767 & 6.40008 & 0.39672 & 22.4321 & 0.07000 & 70.7512 \\
2.52834 & 15916.8588 & 0.22131 & 0.09182965 & 6.40016 & 0.43814 & 22.4376 & 0.07001 & 70.6091 \\
2.52620 & 15980.2464 & 0.22243 & 0.09228624 & 6.40023 & 0.44306 & 22.4426 & 0.07001 & 70.5018 \\
2.52602 & 15991.0386 & 0.22253 & 0.09231518 & 6.40030 & 0.44352 & 22.4476 & 0.07002 & 70.4896 \\
2.52600 & 15991.3786 & 0.22254 & 0.09231887 & 6.40037 & 0.44356 & 22.4525 & 0.07002 & 70.4885 \\
2.52600 & 15991.4820 & 0.22254 & 0.09231907 & 6.40044 & 0.44356 & 22.4575 & 0.07003 & 70.4884 \\
2.52600 & 15991.4826 & 0.22254 & 0.09231911 & 6.40051 & 0.44356 & 22.4625 & 0.07003 & 70.4884 \\
2.52600 & 15991.4842 & 0.22254 & 0.09231911 & 6.40058 & 0.44356 & 22.4674 & 0.07004 & 70.4884 \\
2.526 & 15991.4846 & 0.22254 & 0.09231911 & 6.40065 & 0.44356 & 22.4724 & 0.07004 & 70.4884
\end{tabular}




\begin{tabular}{ccccccccc}
\hline \multicolumn{1}{c}{$f_{\text {bo }}$} & $w_{t}$ & \multicolumn{1}{c}{$t_{t}$} & $\rho_{t}$ & $S$ & $\rho_{s}$ & $t_{s}$ & $P$ \\
\hline 2.110136 & 14478 & 0.25 & 0.1 & 6 & 0.3 & 22.426 & 0.07 & 70 \\
1.93072 & 11638.6104 & 0.22363 & 0.09303018 & 6.00005 & 0.37884 & 22.4310 & 0.07000 & 70.5069 \\
1.92325 & 12499.2393 & 0.22942 & 0.09433318 & 6.00009 & 0.40383 & 22.4356 & 0.07001 & 70.3871 \\
1.92270 & 12507.0797 & 0.23004 & 0.09456108 & 6.00013 & 0.40566 & 22.4399 & 0.070015 & 70.3268 \\
1.92267 & 12511.9668 & 0.23006 & 0.09456719 & 6.00017 & 0.40580 & 22.4442 & 0.07001 & 70.3224 \\
1.92267 & 12511.7904 & 0.23006 & 0.09456829 & 6.00022 & 0.40580 & 22.4484 & 0.07002 & 70.3220 \\
1.92267 & 12511.8316 & 0.23006 & 0.09456829 & 6.00026 & 0.40580 & 22.4527 & 0.07002 & 70.3220 \\
1.92267 & 12511.8288 & 0.23006 & 0.09456830 & 6.00030 & 0.40580 & 22.4570 & 0.07003 & 70.3220 \\
1.92266 & 12511.8297 & 0.23006 & 0.09456830 & 6.00034 & 0.40580 & 22.4613 & 0.07003 & 70.3220 \\
1.92266 & 12511.8300 & 0.23006 & 0.09456830 & 6.00039 & 0.40580 & 22.4655 & 0.07004 & 70.3220 \\
\hline
\end{tabular}

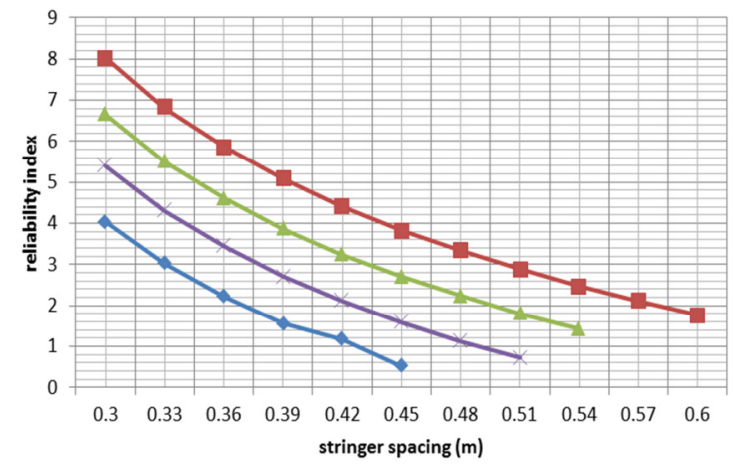

Figure 3 -Structural Safety Index: - Stringer spacing under varying loads.

It can be observed from Table 3 that the major factors which influence the performance function of planks for bridge decks are the grade stress, plank thickness and stringer spacing among other factors. Thus, the effect of these factors on structural safety is examined in the following sections.

\subsubsection{Structural reliability assessment of Nigerian timbers in relation to stringer spacing under constant and varying loads}

Figures 3 and 4 indicate clearly in a pictorial form, the implicit safety or reliability indices in relation to the stringer spacing for each wood class evaluated for use as bridge decks under constant and varying load respectively. It is observed that Nigerian timber species of strength classes $\mathrm{N}_{1}$ and $\mathrm{N}_{2}$, grade $80 \%$ (that is EKKI and APA) can comfortably be used for bridge decks with stringer spacing, $S$, ranging from 0.3 $0.45 \mathrm{~m}$; with EKKI having a structural safety index as high as 8.019 (corresponding probability of failure, $\left.p_{f}=1-\Phi(\beta) \approx 0\right)$ at stringer spacing of $0.3 \mathrm{~m}$, and reliability index of $3.833\left(p_{f} \approx 6.33346 \mathrm{E}-\right.$ 05 ) at stringer spacing of $0.45 \mathrm{~m}$, while for APA, the reliability index is $6.642\left(p_{f} \approx 1.54651 \mathrm{E}-11\right)$ at stringer spacing of $0.3 \mathrm{~m}$, and reliability index of 2.703

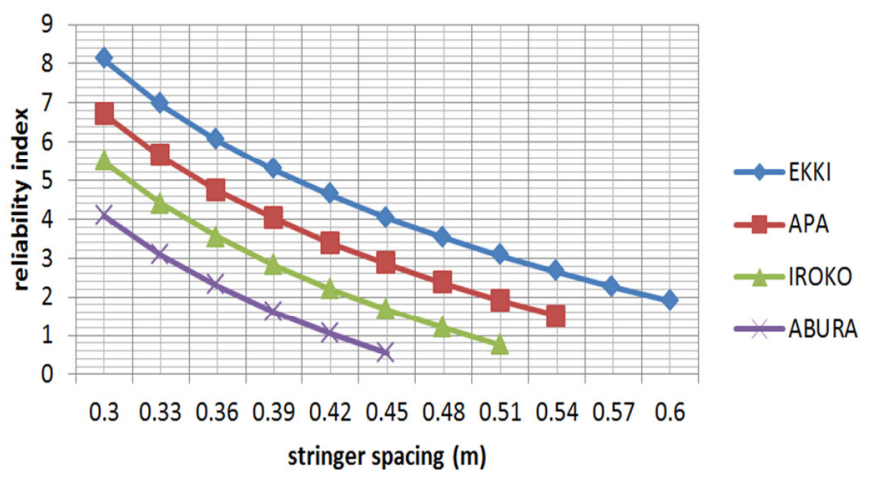

Figure 4-Structural Safety Index: Stringer spacing under constant loads

$\left(p_{f} \approx 0.003436885\right)$ at stringer spacing of $0.45 \mathrm{~m}$. For strength class $\mathrm{N}_{3}$ (IROKO), the reliability index is $5.419\left(p_{f} \approx 3.175224 \mathrm{E}-08\right)$ for timber deck supported on a stringer spaced at $0.3 \mathrm{~m}$, but at any thickness greater than $0.4 \mathrm{~m}$, the reliability index fall below the target probability of 0.25 . Lastly, ABURA has a reliability index of $4.040\left(p_{f} \approx 2.67552 \mathrm{E}-05\right)$ for timber at a stringer spacing of $0.3 \mathrm{~m}$ but at any thickness greater than $0.34 \mathrm{~m}$, the reliability index falls below the target reliability.

\subsubsection{Structural reliability assessment of Nigerian timbers in relation to plank thickness at $0.3 m$ stringer spacing}

Figure 5 indicates clearly in a pictorial form, the indicated safety or reliability indices in relation to plank thickness for each wood class evaluated for use as bridge decks at $0.3 \mathrm{~m}$ stringer spacing.This figure shows that, the strength classes observed can all be used for bridge decking at stringer spacing of $0.3 \mathrm{~m}$. This is because the least of them which is ABURA in strength group $\mathrm{N}_{4}$, has a reliability index of about 5.0 while others are higher this value. 


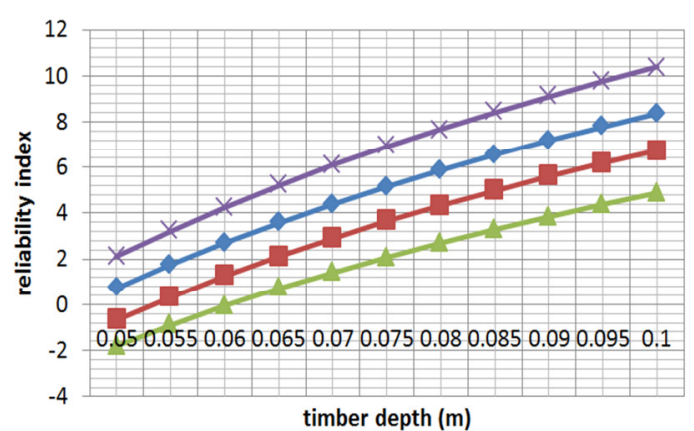

Figure 5 - Reliability index - Plank thickness at $0.3 \mathrm{~m}$ stringer spacing.

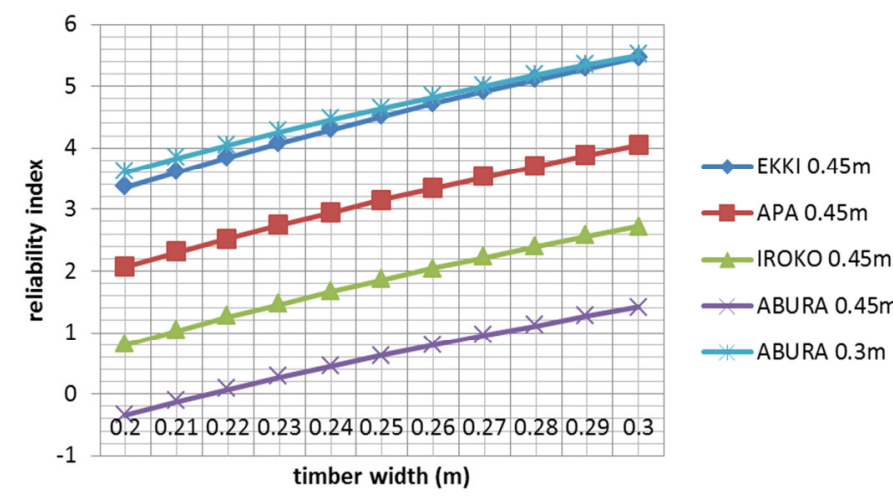

Figure 7 -Structural Safety Index: Plank width.

\subsubsection{Structural reliability assessment of Nigerian timber species in relation to plank thickness at constant stringer spacing of $0.45 \mathrm{~m}$}

Figure 6 indicates clearly in a pictorial form, the indicated safety or reliability indices in relation to plank thickness for each wood class evaluated for use as bridge decks at $0.45 \mathrm{~m}$ stringer spacing. It was observed from the figure, that only Nigerian timber species in strength classes $\mathrm{N}_{1}$ (EKKI) and $\mathrm{N}_{2}$ (APA) can be used for bridge decking at a stringer spacing of $0.45 \mathrm{~m}$. The structural safety indices of IROKO and ABURA are about 2.0 and 1.0 respectively. These values are less than 2.5; but EKKI and APA have safety

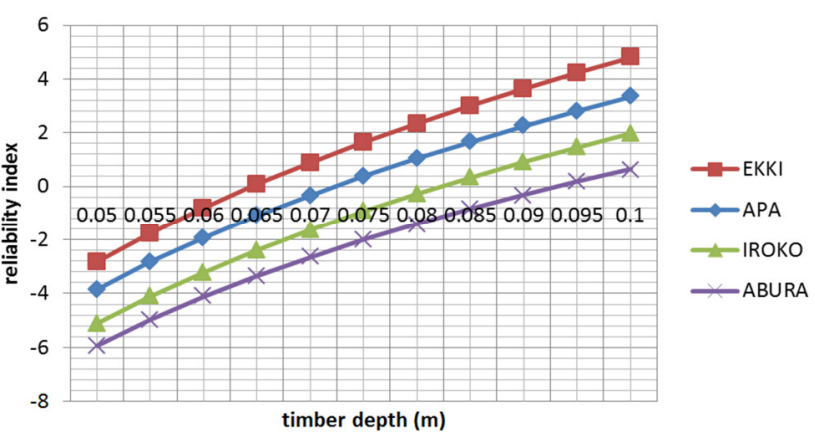

Figure 6 - Structural Safety Index: Plank thickness at $0.45 \mathrm{~m}$ stringer spacing.

indices of about 5.0 and 3.5 respectively at this spacing.

\subsubsection{Structural reliability assessment of Nigerian timbers in relation to plank width at constant stringer spacing}

Figure 7 indicates clearly in a pictorial form, the structural safety or reliability indices in relation to planks width for each wood class evaluated for use as bridge decks at $0.3 \mathrm{~m}$ and $0.45 \mathrm{~m}$ stringer spacing. It is observed that, although the timber width may be reduced for ABURA at a stringer spacing of $0.3 \mathrm{~m}$ to a minimum of $0.2 \mathrm{~m}$, the structure will not meet the target structural safety index or required safety at a stringer spacing of $0.45 \mathrm{~m}$; not even with a timber thickness of $0.1 \mathrm{~m}$ and a width of $0.3 \mathrm{~m}$.

\subsection{Damage accumulation reliability analysis results}

Results for damage safety assessment for the effect of load accumulation over time with reference to bridge load for the four timber species assessed and which are proposed for bridge decks are given in Table 4 . Table 4 shows the general stochastic reliability assessment of four Nigerian timber species representing various strength classes in progressive order; EKKI for strength class $\mathrm{N}_{1}$, APA for class $\mathrm{N}_{2}$, IROKO for class $\mathrm{N}_{3}$ and ABURA for class $\mathrm{N}_{4}$.

Table 4: Damage Accumulation Safety Assessment Of Proposed Species

\begin{tabular}{ccccc}
\hline$t_{f}$ & $\sigma(t)$ & $f_{0}$ & $\beta$ & $p_{f}$ \\
\hline 438000 & 95 & EKKI & 6.812120214 & $3.08433 \mathrm{E}-09$ \\
556617.3 & 118.0818 & 12877.62701 & 7.885119 & $2.89 \mathrm{E}-12$ \\
854777.4 & 128.7875 & 14500.72 & 7.885175 & $2.89 \mathrm{E}-12$ \\
964323.2 & 129.0599 & 14665.11 & 7.890448 & $2.78 \mathrm{E}-12$ \\
978154.3 & 129.0197 & 14676.49 & 7.89147 & $2.76 \mathrm{E}-12$ \\
\hline 438000 & 95 & APA & $1.44182 \mathrm{E}-05$ \\
491442 & 109.4275 & 11825.95669 & 5.182466392 & $1.31 \mathrm{E}-08$ \\
666261.9 & 114.9092 & 12698.86 & 5.564637 & $1.34 \mathrm{E}-08$ \\
706784.6 & 114.9654 & 12760.99 & 5.561052 & $1.33 \mathrm{E}-08$ \\
709507.5 & 114.9578 & 12763.81 & 5.562589 & $1.33 \mathrm{E}-08$
\end{tabular}




\begin{tabular}{|c|c|c|c|c|}
\hline$t_{f}$ & $\sigma(t)$ & $f_{0}$ & $\beta$ & $p_{f}$ \\
\hline \multicolumn{5}{|c|}{ IROKO } \\
\hline 438000 & 95 & 18507 & 3.019065248 & 0.00126778 \\
\hline 460607 & 104.8846 & 11281.94424 & 3.747934 & $8.91 \mathrm{E}-05$ \\
\hline 572768.8 & 107.359 & 11732.81 & 3.74454 & $9.04 \mathrm{E}-05$ \\
\hline 589840.6 & 107.3488 & 11757.04 & 3.745052 & $9.02 \mathrm{E}-05$ \\
\hline 590489.2 & 107.3469 & 11757.78 & 3.745078 & $9.02 \mathrm{E}-05$ \\
\hline \multicolumn{5}{|c|}{ ABURA } \\
\hline 438000 & 95 & 14478 & 1.625037246 & 0.052077311 \\
\hline 437605.9 & 99.26417 & 10638.01509 & 1.893234 & 0.029163 \\
\hline 486483.7 & 99.92608 & 10791.19 & 1.892287 & 0.029226 \\
\hline 489753.4 & 99.92157 & 10795.94 & 1.892337 & 0.029223 \\
\hline 489796.9 & 99.92146 & 10796 & 1.892337 & 0.029223 \\
\hline
\end{tabular}

\section{OBSERVATIONS}

It is observed from the stochastic assessment, that the major factor influencing the performance function of timber bridge decks in accordance to AASTHO LRFD[12] are strength classes, timber thicknesses and stringer spacing among others. The structural safety indices were found to strongly depend on strength classes: with EKKI (class $\mathrm{N}_{1}$ ) having the highest structural safety index of approximately 3.8491 at an appreciable possible point of failure with a timber depth of $0.087 \mathrm{~m}$, width of $0.205 \mathrm{~m}$ and stringer spacing of $0.516 \mathrm{~m}$ under an ultimate wheel load of $70.692 \mathrm{kN}$.This is followed by APA (class $\mathrm{N}_{2}$ ) with reliability index of 3.187, timber thickness of $0.090 \mathrm{~m}$, width of $0.214 \mathrm{~m}$, stringer spacing of $0.478 \mathrm{~m}$ and ultimate wheel load of $70.599 \mathrm{kN}$ at the possible point of failure, then IROKO $\left(\mathrm{N}_{3}\right)$ with reliability index of 2.526, timber thickness $0.092 \mathrm{~m}$, width of $0.222 \mathrm{~m}$, stringer spacing of $0.444 \mathrm{~m}$ and ultimate load of $70.488 \mathrm{kN}$ at the possible point of failure and lastly ABURA $\left(\mathrm{N}_{4}\right)$ with reliability index of 1.923 , timber thickness of $0.095 \mathrm{~m}$, width of $0.230 \mathrm{~m}$ stringer spacing of $0.406 \mathrm{~m}$ under an ultimate load of $70.322 \mathrm{kN}$ at possible point of failure. Nowak and Saraf [11] states that stringers are spaced at, $0.3 \mathrm{mto} 0.6 \mathrm{~m}$ center to center, but mostly $0.3 \mathrm{~m}$ to $0.45 \mathrm{~m}$, while the planks are typically $0.1 \mathrm{~m} \times 0.25 \mathrm{~m}$ or $0.1 \mathrm{~m} \times 0.3 \mathrm{~m}$. Thus, in relation to this, it will be observed that Nigerian timber species with strength class $\mathrm{N}_{4}$ or lower will not be suitable for use as bridge decks, but there exist the possibility of using strength class $\mathrm{N}_{4}$, grade $80 \%$ for bridge decks at stringer spacings lower than $0.4 \mathrm{~m}$ with an appreciable increased timber thickness above $0.23 \mathrm{~m}$.

However, it is observed from Figure 5, that timber thickness for Nigerian timber species in strength class $\mathrm{N}_{2}$ (APA) when used as bridge decks can be reduced to $0.06 \mathrm{~m}$ with a structural safety or reliability index of 2.702 at $0.3 \mathrm{~m}$ stringer spacing, and that of strength class $\mathrm{N}_{3}$ (IROKO), can be reduced to $0.07 \mathrm{~m}$ with reliability index of 2.904 at $0.3 \mathrm{~m}$ stringer spacing, while that of strength class $\mathrm{N}_{4}$ (ABURA), can be reduced to $0.08 \mathrm{~m}$ at stringer spacing of $0.3 \mathrm{~m}$ with reliability index of 2.707 .

Lastly, Table 4 shows the reliability and approximate probability of failure over a predictable design period of 50 years. This probability of failure is based on the effect of load accumulation over time. Thus, it is clear that the possibility of failure over time still depends on the strength classes; with timber within the high strength classes having low probability of failure over time compared to timber with low strength classes: that is, strength class $\mathrm{N}_{1}$ (for example, EKKI) with probability of failure, $p_{f}=1-\Phi(\beta) \approx 2.76 \mathrm{E}-12$ over a period of 978154 hours (100 years), strength class $\mathrm{N}_{3}$ (APA timber) with probability of failure, $p_{f} \approx 1.33 \mathrm{E}-08$ over a period of 709508 hours (80 years), strength class $\mathrm{N}_{3}$ (IROKO timber) with probability of failure, $p_{f} \approx 9.02 \mathrm{E}-05$ over a period of 590489 hours (65 years) and strength class $\mathrm{N}_{4}$ (ABURA timber) with probability of failure, $p_{f} \approx 0.029223$ over a period of 489797 hours (55 years).

\section{CONCLUSION}

This study assessed the possibility of using various Nigerian timber species as sustainable bridge deck materials and checks the long time viability of using them for bridge decks. Therefore, some suitable species were identified as possible source of sustainable and renewable planks for bridge decks. These include timbers within the range of strength classes $\mathrm{N}_{1}$ to $\mathrm{N}_{4}$ out of the listed seven strength classes obtainable in the country. However, other classes may be used if they are upgraded to the requirement of strength classes $N_{1}$ to $N_{4}$ by available engineering treatments for timber. 
The recommended strength classes with associated material properties can be a source of sustainable bridge deck materials over a reasonable period of time as indicated by the probability of failure as a result of damage due to load accumulation. Thus, this will enhance the use of Nigerian timber species and wood resources as innovative, sustainable and cost-effective materials for bridge decks, while promoting interest in the use of wood as a competitive bridge construction material by adding value to the use of local resources, and establishing a means of overcoming exclusion while also strengthening the inclusion of the use of timber in bridge construction industries.

\section{RECOMMENDATION}

The following recommendations should be considered in the construction of timber bridge decks using Nigerian timber species.

1. The most suitable strength classes for bridge decks are timbers with strength class $\mathrm{N}_{1}$ to $\mathrm{N}_{4}$ and any other timber with similar strength characteristics.

2. Timbers with a strength class lower than that of class $\mathrm{N}_{4}$ should not be used for bridge decking, except when adequate engineering treatments have been performed on them in order to upgrade their strength classes to between $\mathrm{N}_{1}$ and $\mathrm{N}_{4}$ inclusive.

3. When using Nigerian timber for bridge decks, the stringers spacing should not be greater than $300 \mathrm{~mm}$ with timber thickness of not less than $100 \mathrm{~mm}$, except for timber with strength class $\mathrm{N}_{1}$, where the spacing can be increased to $450 \mathrm{~mm}$ with a timber thickness not less than $100 \mathrm{~mm}$

4. The width of the planks for the timber decking should not be less than $250 \mathrm{~mm}$.

\section{REFERENCES}

[1] Aguwa J. I. and Sadiku S. Reliability Studies on The Nigerian Ekki Timber As Bridge Beam In Bending Under The Ultimate Limit State Of Loading. Journal of Civil Engineering and Construction Technology, Vol. 2(11), 2011, pp. 253-259.

[2] Adedeji Y. M. D and Ogunsote O. O. Modern Techniques of Using Timber in Building Structures and Components in Nigeria. Proceedings of conference, Department of Architecture, Federal University of Technology, Akure, 2005,

[3] Afolayan J. A. Economic Efficiency Of Glued Joint In Timber Truss Systems. Building And Environment. Vol. 34, 1998, pp 101-107.
[4] Bell K. Timber Bridges. In: Handbook1 Timber Structure, Leonard da Vinci pilot project educational materials for design and testing of timber structures. 2007, pp. 209226

http://fast10.vsb.cz/temtis/documents/handbook1 fin al.pdf Accessed on June 2, 2012

[5] Vermont local road fact sheet, (2008). Modern Timber Bridges An Alternative For Meeting Local Bridge Needs. Scranton Gillette Communications, Inc. Saint Michael's College, Colchester. 2008, pp. 2. www.vermontlocalroads.org Accessed on June 2, 2012

[6] David C. Rapid Bridge Construction Using Timber Components. Wheeler Lumber LLC. 2011. http://www.wheeler-con.com/pdf/Rapid-BridgeConstruction-using-Timber-Components.pdf Accessed on June 2,2012

[7] Aguwa J. I. Reliability Assessment of the Nigerian Apa (Afzelia Bipindensis) Timber Bridge Beam Subjected to Bending and Deflection Under the Ultimate Limit State of Loading. International Journal of Engineering and Technology. Vol. 2 (6), pp 1076-88, 2012.

[8] Lokja A. and Marek, P. Simulation based reliability assessment of timber structures. www.ebookbrowse.com/lokja-pdf-d284399532 Accessed on June 6, 2012

[9] Anagnos T. and Marek P. Application of Simulation Techniques In Teaching Reliability Concepts. $26^{\text {th }}$ Annual Frontiers In Education-Vol 2, pp 950-953, 1996.

[10] Praks P. and Brozovsky J., (2010). Simulation Approaches For The Efficient Probabilistic Reliability Assessment of A Concrete Structure By The SBRA Method. Engineering Mechanics, Vol. 17, Number. 5/6, 2010, pp. 299-305

[11] Nowak A. S.; and Saraf V. Reliability Analysis of Plank Decks for Bridges. Proceedings, National Conference on Wooden Transportation Structures, Madison, WI, pp. 225-231, 1996.

[12] AASHTO LRFD. Specification For Highway Bridges. Washington Dc: American Association Of State Highway Transportation Officials. Pp. 977-1017, 2010

[13] Gerhards C. C. Time-related effects on wood strength: a linear cumulative damage theory. Wood Science; 11(3), pp 139-144, 1979.

[14] Hoffmeyer P. Duration of Load Revisited, wood science and technology, 41, pp. 687-771, 2007.

[15] Melchers R.E. Structural Reliability Analysis and Prediction, 1st Edition, Ellis Horwood Limited, Chichester England. Pp. 69-80, 1987.

[16] CIRAD, IROKO's Datasheet, The main technical characteristics of tropical wood species, 2012. http://tropix.cirad.fr/en/list-of-data-sheets-available Accessed on January 12, 2013.

[17] CIRAD, ABURA's Datasheet, The main technical characteristics of tropical wood species, 2012. http://tropix.cirad.fr/en/list-of-data-sheets-available Accessed on January 12, 2013. 